\title{
Estimativa do consumo relativo de água para a cultura da soja no Estado do Rio Grande do Sul
}

\author{
Estimative of the relative water consumption of soybean in Rio Grande \\ do Sul State, Brazil
}

\author{
Ronaldo Matzenauer ${ }^{1,2}$ Nídio Antonio Barni ${ }^{1}$ \\ Jaime Ricardo Tavares Maluf ${ }^{3}$
}

\section{RESUMO}

Estimou-se o consumo relativo de água (razão ETr/ETm) para o período crítico da cultura da soja em três épocas de semeadura, para dez localidades do Estado do Rio Grande do Sul. A evapotranspiração máxima (ETm) foi estimada utilizando-se o coeficiente de cultura (Kc) e a evapotranspiração real (ETr), calculada pelo balanço hídrico decendial, para o periodo de 1975/76 a 2000/2001. Considerando-se os valores médios dos periodos, o consumo relativo de água variou de 0,46 na época de semeadura de outubro, em Rio Grande, a 0,74 na semeadura de dezembro em Veranópolis. São Gabriel e Rio Grande foram os locais que apresentaram os menores valores de consumo relativo de água, portanto, com maior risco para a produção de grãos. Em anos de forte estiagem, o consumo relativo de água, em algumas situações, foi menor do que 0,20, evidenciando o problema da deficiência hídrica no Estado. Em 46,3\% dos casos analisados, o consumo relativo de água classifica-se como de médio ou alto risco para a cultura da soja (indice ETr $/ E T m \leq 0,60$ durante o periodo critico). A localidade de Rio Grande apresentou 63,3\% dos casos com indice igual ou menor a 0,60, seguido-se São Gabriel com 61,1\%, Encruzilhada do Sul com 52,6\% e Júlio de Castilhos com 50,8\% dos casos. Os locais de menor risco foram Passo Fundo, Veranópolis e Santa Rosa com índices iguais ou menores do que 0,60 ocorrendo em 30,3\%, 37,5\% e $38 \%$ dos casos, respectivamente. A época de semeadura de maior risco por deficiência hídrica para a soja foi a de outubro, enquanto a semeadura de dezembro foi a de menor risco. Para o conjunto dos locais analisados, pode-se esperar redução de rendimento de grãos de soja por deficiência hidrica, em cerca de nove safras a cada vinte, com intensidade variável, dependendo do local, do ano e da época de semeadura.

Palavras-chave: evapotranspiração máxima, soja, evapotranspiração real, evapotranspiração relativa, época de semeadura.

\begin{abstract}
The objective of this work was to estimate the relative water consumption (ETr/ETm) for the critical period of soybean in several sowing dates for ten places of Rio Grande do Sul state, Brazil. The maximum evapotranspiration (ETm) was estimated using the crop coefficient $(K c)$ while the real evapotranspiration (ETr) was estimated through the water balance, calculated for the period from 1975/76 to 2000/2001. Considering the average values of the periods, the relative water consumption varied from 0.46 in the sowing of October, in Rio Grande, to 0.74 in the sowing of December in Veranópolis. São Gabriel and Rio Grande are the places that present the smallest values of relative water consumption, therefore with larger risk for the production of grains. In years of strong drought, the relative water consumption, in some situations, was smaller than 0.20, evidencing the problem of water deficiency. In $46.3 \%$ of the cases the relative water consumption was classified as of high or medium risk (index ETr/ETm $\leq 0.60$ during the critical period). Rio Grande presented $63.3 \%$ of the cases with index equal to or smaller than 0.60, followed by São Gabriel with $61.1 \%$, Encruzilhada do Sul with $52.6 \%$ and Júlio de Castilhos with $50.8 \%$. The places of smaller risk were Passo Fundo, Veranópolis and Santa Rosa, with indexes equal to or smaller than 0.60 happening in $30.3 \%$, $37.5 \%$ and $38 \%$ of the cases, respectively. The sowing date with higher risk was October and with lower risk was December. For the group of the places, it can be expected that every twenty years, in about nine reduction of soybean yield should happen due to water deficiency, with variable intensity, depending on the place, year and sowing date.
\end{abstract}

Key words: maximum evapotranspiration, real evapotranspiratiom, soybean, relative evapotranspiration, sowing date.

\footnotetext{
${ }^{1}$ Engenheiro Agrônomo, Dr., Pesquisador da Fundação Estadual de Pesquisa Agropecuária - FEPAGRO/SCT.

${ }^{2}$ Pesquisador do CNPq. E-mail: ronaldo-matzenauer@fepagro.rs.gov.br Autor para correspondência.

${ }^{3}$ Engenheiro Agrônomo, MSc, Pesquisador da Embrapa Trigo.
} 


\section{INTRODUÇÃO}

A soja é a cultura produtora de grãos que ocupa a maior área cultivada no Estado do Rio Grande do Sul. Na safra 2000/2001 foram colhidos cerca de 2,965 milhões de hectares com uma produção de 6,935 milhões de toneladas de grãos (BISOTTO \& FARIAS, 2001). No entanto, o rendimento de grãos dessa cultura apresenta grandes oscilações entre locais e anos, sendo a variabilidade na distribuição de chuvas, principalmente durante o período de primavera-verão, a principal limitação à expressão do potencial de rendimento da cultura no sul do Brasil (CUNHA et al., 1998). Isto está de acordo com os resultados obtidos anteriormente por BERLATO (1987) e MOTA et al. (1996) os quais indicaram que a disponibilidade hídrica é o principal fator limitante ao rendimento de grãos de soja no Estado do Rio Grande do Sul.

Em uma análise agroclimatológica da necessidade de irrigação da soja no Rio Grande do Sul, MOTA et al. (1996) concluíram que em todas as regiões do Estado há necessidade de irrigação, considerando o período de semeadura recomendado e as cultivares de todos os grupos de maturação. Trabalhos de pesquisa que objetivam a determinação de índices agrometeorológicos visando a minimizar os efeitos do déficit hídrico sobre as culturas, têm aumentado nos últimos anos, propiciando o aperfeiçoamento dos trabalhos de zoneamentos agroclimáticos, com ênfase à redução de riscos, na produção de grãos.

A quantidade de água consumida pela planta em condições naturais de disponibilidade hídrica (evapotranspiração real - ETr) relacionada ao consumo de água sem restrição hídrica (evapotranspiração máxima - ETm) fornece o consumo relativo de água, representado pelo índice ETr/ETm, ou seja, indica a quantidade de água que a planta consome, em relação à quantidade máxima de água que a planta consumiria, na ausência de restrição hídrica. Portanto, é um índice de grande utilidade em estudos agrometeorológicos e tem sido utilizado mais recentemente em trabalhos de zoneamento agroclimático, para a definição de áreas de risco para a produção de grãos.

BERLATO (1987) relacionou o rendimento de grãos da soja com o consumo relativo de água para diversas localidades do RS. Concluiu que o consumo relativo de água explicou 89,86 e $85 \%$ da variação do rendimento de grãos de soja dos grupos de maturação precoce, médio e tardio, respectivamente, durante o período crítico da cultura (do início da floração até o início do enchimento de grãos $-\mathrm{R}_{1}-\mathrm{R}_{5}$ ). Os modelos agrometeorológicos, relacionando o rendimento de grãos com o índice ETr/ETm durante o período crítico da cultura, podem ser utilizados para a estimativa do rendimento de grãos de soja, tendo a vantagem, ainda, de estimar com uma antecedência de aproximadamente 30 dias da maturação da cultura, portanto, bem antes da colheita.

MATZENAUER et al. (1995) determinaram o consumo relativo de água para a cultura do milho para vários locais e anos, encontrando alta associação entre a variável e o rendimento de grãos. Os autores concluíram que o consumo relativo de água é a variável mais eficiente para indicar as variações de rendimento de grãos de milho entre épocas de semeadura, anos e locais no Estado do Rio Grande do Sul.

$\mathrm{O}$ índice ETr/ETm tem sido utilizado para a definição de áreas de cultivo, visando à redução de riscos por estiagem. MATZENAUER et al. (2002) definiram três índices de risco para a produção de soja no Rio Grande do Sul, que podem ser associados às áreas de produção. Áreas de baixo risco - áreas onde o consumo relativo de água - índice ETr/ETm - é maior que 0,60 ; áreas de risco médio - áreas onde o consumo relativo de água é igual ou menor que 0,60 e igual ou maior que 0,40 ; e áreas de alto risco - áreas onde o consumo relativo de água é menor que 0,40 .

Este trabalho teve o objetivo de estimar o consumo relativo de água para a cultura da soja em diferentes épocas de semeadura, para dez localidades do Estado do Rio Grande do Sul, visando fornecer informações úteis aos estudos de zoneamentos agroclimáticos e definição da época de semeadura de menor risco para a produção dessa cultura.

\section{MATERIAL E MÉTODOS}

O consumo relativo de água para a cultura da soja foi calculado para dez localidades do Estado do Rio Grande do Sul (Tabela 1), num período variável de 19 a 26 anos, em função da disponibilidade de dados meteorológicos. Os dados meteorológicos foram obtidos no Banco de Dados do Laboratório de Agrometeorologia da Fundação Estadual de Pesquisa Agropecuária-FEPAGRO/SCT, RS.

A evapotranspiração (ETm) máxima da cultura foi estimada a partir da relação:

$$
\mathrm{ETm}=\mathrm{Kc} \text {. ETo }
$$

Onde Kc é o coeficiente de cultura (BERLATO et al., 1986) e ETo é a evapotranspiração de referência calculada pelo método de PENMAN (1956). A evapotranspiração real foi calculada pelo uso do balanço hídrico decendial (THORNTHWAITE \& MATHER, 1955), utilizando-se uma capacidade de armazenamento de água disponível no solo (CAD) de 
Tabela 1 - Localidades e período de cálculo do consumo relativo de água para a cultura da soja, no Estado do Rio Grande do Sul.

\begin{tabular}{|c|c|c|c|c|c|}
\hline \multirow{2}{*}{ Localidade } & \multirow{2}{*}{ Região climática } & \multirow{2}{*}{ Período calculado } & \multicolumn{3}{|c|}{ Coordenadas geográficas } \\
\hline & & & Altitude & Latitude (S) & Longitude (W) \\
\hline Cruz Alta & Planalto & $75 / 76-96 / 97$ & 473 & $28^{\circ} 38^{\prime} 21^{\prime \prime}$ & $53^{\circ} 36^{\prime} 42^{\prime}$, \\
\hline Júlio de Castilhos & Planalto & $75 / 76-95 / 96$ & 514 & $29^{\circ} 13^{\prime} 26^{\prime \prime}$ & $53^{\circ} 40^{\prime} 45^{\prime}$, \\
\hline Passo Fundo & Planalto & $75 / 76-96 / 97$ & 709 & $28^{\circ} 15^{\prime} 41^{\prime}$ & $52^{\circ} 24^{\prime} 45^{\prime}$ \\
\hline Santa Rosa & Missões & $75 / 76-98 / 99$ & 273 & $27^{\circ} 51^{\prime} 50^{\prime \prime}$ & $54^{\circ} 29^{\prime} 03^{\prime}$, \\
\hline São Borja & Vale do Uruguai & $75 / 76-97 / 98$ & 99 & $28^{\circ} 39^{\prime} 44^{\prime \prime}$ & $56^{\circ} 00^{\prime} 44^{\prime}$, \\
\hline São Gabriel & Depressão Central & $75 / 76-99 / 00$ & 109 & $30^{\circ} 20^{\prime} 27^{\prime \prime}$ & $54^{\circ} 19^{\prime} 01^{\prime}$, \\
\hline Taquari & Depressão Central & $75 / 76-00 / 01$ & 76 & $29^{\circ} 48^{\prime} 15^{\prime}$ & $51^{\circ} 49^{\prime} 30^{\prime \prime}$ \\
\hline Rio Grande & Litoral Sul & $75 / 76-98 / 99$ & 15 & $32^{\circ} 01^{\prime} 02^{\prime \prime}$ & $52^{\circ} 09^{\prime} 32^{\prime}$ \\
\hline Encruzilhada do Sul & Serra do Sudeste & 75/76 - 98/99 & 420 & $30^{\circ} 25^{\prime} 35^{\prime}$ & $52^{\circ} 31^{\prime} 20^{\prime \prime}$ \\
\hline Veranópolis & Serra do Nordeste & $75 / 76-98 / 99$ & 705 & $28^{\circ} 56^{\prime} 14^{\prime \prime}$ & $51^{\circ} 33^{\prime} 11^{\prime \prime}$ \\
\hline
\end{tabular}

$100 \mathrm{~mm}$. O índice ETr/ETm foi calculado para as épocas de semeadura de outubro, novembro e dezembro, centralizadas no dia primeiro do mês.

A estimativa do consumo relativo de água foi obtida somente para o período crítico da cultura, ou seja, do início da floração até o início do enchimento de grãos $\left(\mathrm{R}_{1}-\mathrm{R}_{5}\right)$, conforme BERLATO (1987), que obteve para este subperíodo as maiores associações entre o consumo relativo de água e o rendimento de grãos de soja, em um estudo realizado para as condições do Rio Grande do Sul. Nos cálculos, utilizou-se a fenologia média referente a cultivares de grupo de maturação de ciclo médio, conforme MATZENAUER et al. (1998).

\section{RESULTADOS E DISCUSSÃO}

As estimativas do consumo relativo de água no período crítico da soja, para as dez localidades avaliadas, bem como os valores médios e o desvio padrão de cada período em cada época de semeadura, são apresentados nas tabelas 2 a 4 . Considerando-se os valores médios dos períodos, o consumo relativo de água variou de 0,46 na época de semeadura de outubro na localidade de Rio Grande, a 0,74 na época de semeadura de dezembro em Veranópolis. Rio Grande, São Gabriel, Encruzilhada do Sul e Júlio de Castilhos foram as localidades que apresentaram os menores valores de consumo relativo de água, portanto, com maior risco para a produção de grãos.

Os valores de consumo relativo de água para a cultura da soja são menores do que para a cultura do milho (MATZENAUER, 2002). O autor encontrou valores de consumo relativo de água para o milho que variaram de 0,53 a 0,84 para os mesmos locais avaliados neste estudo, em várias épocas de semeadura. Os valores mais baixos do índice encontrados para a cultura da soja, são atribuídos aos valores mais elevados de consumo de água da cultura (MATZENAUER et al., 2002). Apesar disso, os danos causados pelas estiagens na cultura da soja, em geral, não são tão severos quanto os que afetam a cultura de o milho, pelo fato do milho apresentar um período crítico mais curto, e com maior sensibilidade ao déficit hídrico comparado com a soja. Por isso, normalmente, dependendo do período em que ocorrem e da época de semeadura, as estiagens afetam mais as safras de milho no Estado, com maiores reduções de rendimento.

Em anos de ocorrência de forte estiagem, o consumo relativo de água, em algumas situações, foi menor do que 0,20. Estes índices, de acordo com modelos agrometeorológicos de previsão de rendimento ajustados por BERLATO (1987), estão associados a reduções de mais de $70 \%$ do rendimento de grãos da cultura da soja.

A época de semeadura de maior risco por deficiência hídrica para a cultura da soja é a de início de outubro, que em todos os locais apresentou o menor consumo relativo de água, seguindo-se a semeadura de novembro, sendo a época de dezembro a de menor risco para a cultura. Estes resultados estão de acordo com o calendário de semeadura da soja para o Rio Grande do Sul (BARNI \& MATZENAUER, 2000), onde as épocas preferenciais, para todas as regiões, não incluem a semeadura de início de outubro, sendo a semeadura de início de dezembro incluída em todas as regiões. CUNHA et al. (1998) observaram menor perda de rendimento potencial de soja semeada na época de início de dezembro, quando comparada com a semeada no início de outubro, em um estudo realizado para diversas localidades do Estado. 
Tabela 2 - Estimativas do consumo relativo de água (índice ETr/ETm) para o período crítico da soja $\left(\mathrm{R}_{1}-\mathrm{R}_{5}\right)$, em diferentes anos e épocas de semeadura, para Cruz Alta, Júlio de Castilhos, Passo Fundo e Santa Rosa, RS.

\begin{tabular}{|c|c|c|c|c|c|c|c|c|c|c|c|c|}
\hline \multirow{3}{*}{ Ano } & \multicolumn{3}{|c|}{ Cruz Alta } & \multicolumn{3}{|c|}{ Júlio de Castilhos } & \multicolumn{3}{|c|}{ Passo Fundo } & \multicolumn{3}{|c|}{ Santa Rosa } \\
\hline & \multicolumn{3}{|c|}{ Época de semeadura } & \multicolumn{3}{|c|}{ Época de semeadura } & \multicolumn{3}{|c|}{ Época de semeadura } & \multicolumn{3}{|c|}{ Época de semeadura } \\
\hline & out & nov & dez & out & nov & $\operatorname{dez}$ & out & nov & $\operatorname{dez}$ & out & nov & dez \\
\hline $75 / 76$ & 0,71 & 0,95 & 0,86 & 0,66 & 0,86 & 0,74 & 0,77 & 0,85 & 0,65 & 0,79 & 0,69 & 0,73 \\
\hline $76 / 77$ & 0,76 & 0,84 & 0,82 & 0,58 & 0,69 & 0,66 & 0,85 & 0,96 & 0,94 & - & - & - \\
\hline $77 / 78$ & 0,29 & 0,32 & 0,39 & 0,38 & 0,49 & 0,51 & 0,58 & 0,47 & 0,40 & 0,35 & 0,36 & 0,45 \\
\hline $78 / 79$ & 0,22 & 0,19 & 0,55 & 0,17 & 0,11 & 0,35 & 0,25 & 0,15 & 0,48 & 0,07 & 0,35 & 0,46 \\
\hline $79 / 80$ & 0,53 & 0,32 & 0,24 & 0,42 & 0,19 & 0,17 & 0,82 & 0,64 & 0,72 & 0,56 & 0,39 & 0,45 \\
\hline $80 / 81$ & 0,83 & 0,93 & 0,97 & 0,67 & 0,72 & 0,82 & 0,84 & 0,84 & 0,81 & 0,51 & 0,58 & 0,64 \\
\hline $81 / 82$ & 0,35 & 0,29 & 0,60 & 0,26 & 0,39 & 0,79 & 0,63 & 0,40 & 0,38 & 0,24 & 0,53 & 0,76 \\
\hline $82 / 83$ & - & - & - & 0,56 & 0,51 & 0,76 & 0,62 & 0,56 & 0,71 & 0,75 & 0,90 & 0,81 \\
\hline $83 / 84$ & 0,62 & 0,99 & 0,83 & 0,63 & 0,89 & 0,91 & 0,71 & 0,82 & 0,80 & 1,00 & 0,80 & 0,62 \\
\hline $84 / 85$ & 0,22 & 0,28 & 0,62 & 0,32 & 0,37 & 0,55 & 0,37 & 0,46 & 0,69 & 0,57 & 0,70 & 0,94 \\
\hline $85 / 86$ & 0,26 & 0,60 & 0,63 & 0,17 & 0,20 & 0,34 & 0,41 & 0,31 & 0,29 & 0,46 & 0,35 & 0,60 \\
\hline $86 / 87$ & 0,66 & 0,89 & 0,86 & 0,56 & 0,64 & 0,57 & 0,63 & 0,74 & 0,76 & 0,82 & 0,87 & 0,95 \\
\hline $87 / 88$ & 0,39 & 0,59 & 0,67 & 0,39 & 0,56 & 0,70 & 0,69 & 0,79 & 0,68 & 0,35 & 0,55 & 0,37 \\
\hline $88 / 89$ & 0,54 & 0,69 & 0,76 & 0,52 & 0,69 & 0,66 & 0,93 & 0,94 & 0,94 & - & - & - \\
\hline $89 / 90$ & 0,71 & 0,86 & 0,80 & 0,62 & 0,65 & 0,59 & 0,79 & 0,89 & 0,88 & 0,83 & 0,76 & 0,63 \\
\hline 90/91 & - & - & - & 0,43 & 0,34 & 0,41 & 0,33 & 0,45 & 0,58 & 0,33 & 0,32 & 0,32 \\
\hline $91 / 92$ & - & - & - & 0,67 & 0,80 & 1,00 & 0,83 & 0,84 & 0,97 & 0,58 & 0,78 & 0,99 \\
\hline $92 / 93$ & 0,76 & 0,86 & 0,66 & 0,62 & 0,71 & 0,70 & 0,86 & 0,99 & 0,96 & 0,97 & 0,76 & 0,72 \\
\hline $93 / 94$ & 0,57 & 0,58 & 0,98 & 0,63 & 0,52 & 0,76 & 0,59 & 0,48 & 0,76 & 0,61 & 1,00 & 0,93 \\
\hline $94 / 95$ & 0,70 & 0,50 & 0,49 & 0,55 & 0,75 & 0,92 & 1,00 & 0,93 & 0,81 & 0,84 & 0,74 & 0,75 \\
\hline $95 / 96$ & 0,37 & 0,78 & 0,95 & 0,42 & 0,71 & 1,00 & 0,40 & 0,80 & 0,94 & 0,81 & 0,92 & 0,88 \\
\hline $96 / 97$ & 0,69 & 0,84 & 0,98 & - & - & - & 0,64 & 0,75 & 0,87 & 0,79 & 0,91 & 0,85 \\
\hline $97 / 98$ & - & - & - & - & - & - & - & - & - & 0,83 & 0,91 & 0,88 \\
\hline 98/99 & - & - & - & - & - & - & - & - & - & 0,46 & 0,66 & 0,73 \\
\hline Média & 0,54 & 0,65 & 0,72 & 0,49 & 0,56 & 0,66 & 0,66 & 0,68 & 0,73 & 0,61 & 0,67 & 0,70 \\
\hline $\mathrm{s}$ & 0,20 & 0,26 & 0,21 & 0,16 & 0,22 & 0,22 & 0,21 & 0,24 & 0,20 & 0,25 & 0,22 & 0,20 \\
\hline
\end{tabular}

$\mathrm{R}_{1}-\mathrm{R}_{5}$ - início da floração até início de enchimento de grãos

$\mathrm{s}$ - desvio padrão

- ausência de dados

Na tabela 5, é apresentado um resumo da análise do consumo relativo de água para a cultura da soja nos diversos locais. Verifica-se que $46,3 \%$ das situações (locais x épocas $\mathrm{x}$ anos) apresentaram consumo relativo de água classificado como de alto ou médio risco (índice $\mathrm{ETr} / \mathrm{ETm} \leq 0,60$ durante o período crítico) conforme a classificação das áreas de risco (MATZENAUER, et al., 2002). A localidade de Rio Grande apresentou $63,3 \%$ dos casos com índice menor ou igual a 0,60 , evidenciando uma região de alto risco para a produção de soja, seguida de São Gabriel com 61,1 \% dos casos, Encruzilhada do Sul com 52,6 \% e Júlio de Castilhos com 50,8 \%. Isto significa que existe uma baixa probabilidade de ocorrer anos com adequada disponibilidade hídrica durante o subperíodo $\mathrm{R}_{1}-\mathrm{R}_{5}$ de desenvolvimento da soja nestes locais, sendo de $36,7 \%, 38,9 \%, 47,4 \%$ e $49,2 \%$, respectivamente. BARNI \& MATZENAUER (2000) estimaram as perdas de rendimento potencial da soja por deficiência hídrica, em diversas localidades do Rio Grande do Sul. Das localidades avaliadas, as que apresentaram as maiores perdas de rendimento foram Bagé, Encruzilhada do Sul e São Borja.

Os locais de menor risco são Passo Fundo, Veranópolis e Santa Rosa, com índices menores que 0,60 ocorrendo em $30,3 \%, 37,5 \%$ e $38 \%$ dos casos, respectivamente. Ou seja, existe uma probabilidade maior (de $69,7 \%, 62,5 \%$ e de $62 \%$ dos anos, respectivamente) de ocorrer boa disponibilidade hídrica durante o período crítico da cultura da soja nos locais citados. Os resultados obtidos por CUNHA et al. (1998) indicam diferenças regionais na magnitude de perda de rendimento potencial na cultura da soja 
Tabela 3 - Estimativas do consumo relativo de água (índice ETr/ETm) para o período crítico da soja $\left(\mathrm{R}_{1}-\mathrm{R}_{5}\right)$, em diferentes anos e épocas de semeadura, para São Borja, São Gabriel, Taquari e Rio Grande, RS.

\begin{tabular}{|c|c|c|c|c|c|c|c|c|c|c|c|c|}
\hline \multirow{3}{*}{ Ano } & \multicolumn{3}{|c|}{ São Borja } & \multicolumn{3}{|c|}{ São Gabriel } & \multicolumn{3}{|c|}{ Taquari } & \multicolumn{3}{|c|}{ Rio Grande } \\
\hline & \multicolumn{3}{|c|}{ Época de semeadura } & \multicolumn{3}{|c|}{ Época de semeadura } & \multicolumn{3}{|c|}{ Época de semeadura } & \multicolumn{3}{|c|}{ Época de semeadura } \\
\hline & out & nov & $\operatorname{dez}$ & out & nov & dez & out & nov & dez & out & nov & dez \\
\hline $75 / 76$ & 0,85 & 0,85 & 0,85 & 0,64 & 0,45 & 0,46 & 0,62 & 0,32 & 0,41 & 0,34 & 0,54 & 0,29 \\
\hline $76 / 77$ & - & - & - & 0,73 & 0,57 & 0,51 & 0,92 & 0,91 & 0,92 & 0,81 & 0,72 & 0,75 \\
\hline $77 / 78$ & 0,32 & 0,22 & 0,29 & 0,31 & 0,34 & 0,15 & 0,65 & 0,58 & 0,43 & 0,13 & 0,39 & 0,78 \\
\hline $78 / 79$ & 0,10 & 0,47 & 0,61 & 0,06 & 0,12 & 0,32 & 0,08 & 0,21 & 0,44 & 0,24 & 0,13 & 0,31 \\
\hline $79 / 80$ & 0,28 & 0,38 & 0,55 & 0,18 & 0,28 & 0,46 & 0,62 & 0,50 & 0,56 & 0,49 & 0,43 & 0,37 \\
\hline $80 / 81$ & 0,76 & 0,85 & 0,73 & 0,57 & 0,64 & 0,58 & 0,65 & 0,84 & 0,80 & 0,32 & 0,39 & 0,67 \\
\hline $81 / 82$ & 0,27 & 0,46 & 0,51 & 0,34 & 0,82 & 0,74 & 0,31 & 0,48 & 0,55 & - & - & - \\
\hline $82 / 83$ & 0,45 & 0,68 & 0,62 & 0,54 & 0,82 & 0,84 & 0,39 & 0,59 & 0,72 & - & - & - \\
\hline $83 / 84$ & 0,74 & 0,70 & 0,58 & 0,80 & 0,74 & 0,61 & 0,76 & 0,74 & 0,64 & 0,57 & 0,68 & 0,78 \\
\hline $84 / 85$ & 0,21 & 0,58 & 0,75 & 0,18 & 0,19 & 0,28 & 0,32 & 0,26 & 0,28 & 0,23 & 0,38 & 0,31 \\
\hline $85 / 86$ & - & - & - & 0,42 & 0,43 & 0,38 & 0,33 & 0,32 & 0,52 & 0,32 & 0,66 & 0,68 \\
\hline $86 / 87$ & 0,76 & 0,67 & 0,57 & 0,58 & 0,31 & 0,41 & 0,74 & 0,68 & 0,73 & 0,61 & 0,34 & 0,39 \\
\hline $87 / 88$ & 0,56 & 0,58 & 0,53 & 0,50 & 0,45 & 0,29 & 0,71 & 0,58 & 0,52 & 0,51 & 0,56 & 0,55 \\
\hline $88 / 89$ & 0,81 & 0,66 & 0,52 & - & - & - & 0,75 & 0,72 & 0,54 & 0,30 & 0,26 & 0,24 \\
\hline $89 / 90$ & 0,44 & 0,45 & 0,61 & 0,52 & 0,82 & 0,72 & 0,43 & 0,54 & 0,64 & 0,12 & 0,30 & 0,62 \\
\hline $90 / 91$ & 0,28 & 0,43 & 0,37 & 0,19 & 0,24 & 0,21 & 0,30 & 0,33 & 0,33 & - & - & - \\
\hline $91 / 92$ & 0,77 & 0,87 & 1,00 & 0,58 & 0,71 & 0,63 & 0,70 & 0,83 & 0,75 & - & - & - \\
\hline $92 / 93$ & 0,97 & 0,65 & 0,58 & 0,72 & 0,59 & 0,56 & 0,85 & 0,60 & 0,50 & 0,55 & 0,51 & 0,50 \\
\hline $93 / 94$ & 0,43 & 0,86 & 0,83 & 0,51 & 0,83 & 0,75 & 0,45 & 0,78 & 0,86 & 0,36 & 0,35 & 0,63 \\
\hline $94 / 95$ & 0,65 & 0,58 & 0,77 & 0,49 & 0,42 & 0,61 & 0,64 & 0,87 & 0,88 & 0,70 & 0,47 & 0,49 \\
\hline $95 / 96$ & 0,75 & 1,00 & 0,92 & 0,70 & 0,70 & 0,49 & 0,83 & 0,90 & 0,77 & 0,55 & 0,62 & 0,66 \\
\hline $96 / 97$ & 0,62 & 0,67 & 0,88 & 0,28 & 0,65 & 0,93 & 0,71 & 0,82 & 0,85 & 0,26 & 0,41 & 0,74 \\
\hline $97 / 98$ & 0,84 & 0,91 & 0,91 & 0,90 & 0,88 & 0,90 & 0,90 & 0,88 & 0,90 & 0,94 & 1,00 & 0,99 \\
\hline 98/99 & - & - & - & 0,40 & 0,62 & 0,76 & 0,56 & 0,83 & 0,79 & 0,87 & 0,92 & 0,75 \\
\hline $99 / 00$ & - & - & - & 0,38 & 0,51 & 0,72 & 0,48 & 0,48 & 0,59 & - & - & - \\
\hline $00 / 01$ & - & - & - & - & - & - & 0,88 & 0,87 & 0,85 & - & - & - \\
\hline Média & 0,56 & 0,64 & 0,67 & 0,48 & 0,55 & 0,55 & 0,60 & 0,63 & 0,65 & 0,46 & 0,50 & 0,58 \\
\hline $\mathrm{s}$ & 0,25 & 0,20 & 0,19 & 0,21 & 0,22 & 0,22 & 0,22 & 0,22 & 0,19 & 0,24 & 0,22 & 0,21 \\
\hline
\end{tabular}

$\mathrm{R}_{1}-\mathrm{R}_{5}$ - início da floração até início de enchimento de grãos

$\mathrm{S}$ - desvio padrão

- ausência de dados

por deficiência hídrica no Estado. Os autores observaram, ainda, que existe um gradiente de perda de rendimento, com aumento de magnitude no sentido de nordeste para sudoeste. Para o conjunto dos locais analisados neste estudo, pode-se deduzir que, em nove anos a cada vinte, deve ocorrer redução de rendimento de grãos de soja, com intensidade variável, dependendo do local, do ano e da época de semeadura.

Os índices ETr/ETm apresentados podem ser utilizados para a estimativa do potencial de rendimento de grãos em cada região e para a previsão de safras agrícolas, utilizando-se modelos agrometeorológicos ajustados para a cultura da soja. Além disso, podem ser uma ferramenta importante para o aperfeiçoamento dos zoneamentos agroclimáticos, possibilitando, ainda, a definição e escolha da época de semeadura de menor risco para a produção de grãos em cada região.

Os dados apresentados evidenciaram, com clareza, o problema da deficiência hídrica para a cultura da soja no Rio Grande do Sul. Ficou caracterizada a ocorrência de períodos de disponibilidade hídrica limitantes para essa cultura, para $46,3 \%$ das situações analisadas, em média (Tabela 5). Apenas em $11 \%$ das situações os valores do consumo relativo de água foram iguais ou superiores a 0,90 , ou seja, com uma deficiência hídrica igual ou menor a $10 \%$ durante o período crítico, a qual não apresenta risco para a produção de grãos. É possível concluir que o Rio Grande do Sul continuará perdendo 
quantidades significativas de grãos causadas por estiagens, com reflexos negativos na economia do Estado. As instituições de pesquisa e extensão rural vem estudando e debatendo este tema há vários anos, independentemente da ocorrência do fenômeno, e alertando para a necessidade de elaboração de um programa de desenvolvimento que contemple um plano abrangente de irrigação, principalmente para as regiões que apresentam maior potencial de rendimento, mas que apesar disso, necessitam com freqüência de suplementação hídrica para proporcionar maior rendimento e maior estabilidade das safras.

Considerando-se que a semeadura de início de outubro apresenta maior risco para a produção de grãos, deve-se dar preferência, nestes

Tabela 4 - Estimativas do consumo relativo de água $(\mathrm{ETr} / \mathrm{ETm})$ para o período crítico da soja $\left(\mathrm{R}_{1}-\mathrm{R}_{5}\right)$, em diferentes anos e épocas de semeadura, para Encruzilhada do Sul e Veranópolis, RS.

\begin{tabular}{lcccccc}
\hline & \multicolumn{2}{c}{ Encruzilhada do Sul } & \multicolumn{3}{c}{ Veranópolis } \\
\cline { 2 - 7 } Ano & \multicolumn{2}{c}{ Época de semeadura } & \multicolumn{2}{c}{ Época de semeadura } \\
\cline { 2 - 7 } & out & nov & dez & out & nov & dez \\
\hline $75 / 76$ & 0,37 & 0,55 & 0,36 & 0,75 & 0,95 & 0,86 \\
$76 / 77$ & 0,76 & 0,85 & 0,91 & 0,83 & 0,88 & 0,75 \\
$77 / 78$ & 0,28 & 0,56 & 0,66 & 0,73 & 0,75 & 0,64 \\
$78 / 79$ & - & - & - & 0,40 & 0,24 & 0,44 \\
$79 / 80$ & 0,53 & 0,44 & 0,41 & 0,94 & 0,96 & 0,95 \\
$80 / 81$ & 0,76 & 0,84 & 0,89 & 0,96 & 0,92 & 0,93 \\
$81 / 82$ & 0,33 & 0,35 & 0,59 & 0,33 & 0,31 & 0,53 \\
$82 / 83$ & 0,57 & 0,64 & 0,78 & 0,68 & 0,57 & 0,75 \\
$83 / 84$ & 0,48 & 0,80 & 0,77 & 0,81 & 0,91 & 0,88 \\
$84 / 85$ & 0,29 & 0,53 & 0,87 & 0,59 & 0,55 & 0,71 \\
$85 / 86$ & 0,36 & 0,40 & 0,52 & 0,29 & 0,21 & 0,31 \\
$86 / 87$ & 0,72 & 0,79 & 0,64 & 0,74 & 0,72 & 0,64 \\
$87 / 88$ & 0,53 & 0,50 & 0,40 & 0,46 & 0,55 & 0,59 \\
$88 / 89$ & 0,25 & 0,45 & 0,34 & 0,46 & 0,70 & 0,77 \\
$89 / 90$ & 0,41 & 0,34 & 0,61 & 0,52 & 0,66 & 0,79 \\
$90 / 91$ & - & - & - & 0,37 & 0,34 & 0,39 \\
$91 / 92$ & 0,45 & 0,68 & 1,00 & 0,83 & 0,83 & 0,95 \\
$92 / 93$ & - & - & - & 0,82 & 0,93 & 0,82 \\
$93 / 94$ & - & - & - & 0,55 & 0,42 & 0,74 \\
$94 / 95$ & - & - & - & 0,89 & 0,93 & 0,89 \\
$95 / 96$ & 0,93 & 0,92 & 0,81 & 0,51 & 0,69 & 0,97 \\
$96 / 97$ & 0,46 & 0,54 & 0,69 & 0,38 & 0,69 & 0,96 \\
$97 / 98$ & 0,74 & 0,91 & 0,93 & 0,77 & 0,88 & 0,94 \\
$98 / 99$ & 0,48 & 0,63 & 0,72 & 0,26 & 0,52 & 0,60 \\
Média & 0,51 & 0,62 & 0,68 & 0,62 & 0,67 & 0,74 \\
\hline & 0,19 & 0,19 & 0,20 & 0,22 & 0,24 & 0,19 \\
\hline & & & & & &
\end{tabular}

$\mathrm{R}_{1}-\mathrm{R}_{5}$ - início da floração até início de enchimento de grãos $\mathrm{S}$ - desvio padrão

- ausência de dados
Tabela 5 - Número total de casos analisados (anos x épocas) e índice $\mathrm{ETr} / \mathrm{ETm}$ crítico (número e percentual) para a cultura da soja, durante o período crítico de desenvolvimento $\left(\mathrm{R}_{1}-\mathrm{R}_{5}\right)$, em dez locais do Rio Grande do Sul.

\begin{tabular}{|c|c|c|c|c|c|}
\hline \multirow{2}{*}{ Local } & \multirow{2}{*}{$\begin{array}{l}\mathrm{n}^{\circ} \mathrm{de} \\
\text { anos }\end{array}$} & \multirow{2}{*}{$\begin{array}{c}\mathrm{n}^{\circ} \mathrm{de} \\
\text { épocas }\end{array}$} & \multirow{2}{*}{$\begin{array}{l}\mathrm{n}^{\circ} \\
\text { total }\end{array}$} & \multicolumn{2}{|c|}{$\mathrm{ETr} / \mathrm{ETm} \leq 0,60 *$} \\
\hline & & & & $\mathrm{n}^{\circ}$ & $\%$ \\
\hline Cruz Alta & 19 & 3 & 57 & 24 & 42,1 \\
\hline Júlio de Castilhos & 21 & 3 & 63 & 32 & 50,8 \\
\hline Passo Fundo & 22 & 3 & 66 & 20 & 30,3 \\
\hline Santa Rosa & 22 & 3 & 66 & 25 & 38,0 \\
\hline São Borja & 21 & 3 & 63 & 28 & 44,4 \\
\hline São Gabriel & 24 & 3 & 72 & 44 & 61,1 \\
\hline Taquari & 26 & 3 & 78 & 35 & 44,9 \\
\hline Rio Grande & 20 & 3 & 60 & 38 & 63,3 \\
\hline Encruzilhada do Sul & 19 & 3 & 57 & 30 & 52,6 \\
\hline Veranópolis & 24 & 3 & 72 & 27 & 37,5 \\
\hline Média/Total & 22 & 3 & 654 & 303 & 46,3 \\
\hline
\end{tabular}

*Índice $\mathrm{ETr} / \mathrm{ETm}$ crítico $\leq 0,60$ para o período crítico de desenvolvimento da cultura;

Período crítico: do início da floração até o início do enchimento de grãos $\left(\mathrm{R}_{1}-\mathrm{R}_{5}\right)$.

casos, a cultivares de ciclo semitardio ou tardio, pois esta prática poderá minimizar os riscos na produção, uma vez que o período crítico da cultura poderá não coincidir com a época de maior demanda evaporativa. Para semeaduras tardias, deve-se aguardar condições adequadas de umidade do solo, visando proporcionar melhores condições para o estabelecimento da cultura e a obtenção de uma adequada população de plantas. No caso de suplementação hídrica, independente da época de semeadura, deve-se sempre dar preferência à irrigação no período crítico da cultura, compreendido entre o início da floração e o início do enchimento de grãos, pois é quando a planta apresenta maior eficiência na utilização da água (BERGONCI et al., 2001).

\section{CONCLUSÕES}

Com base nos resultados apresentados, e para os locais analisados, pode-se concluir que:

1. É freqüente a ocorrência de deficiência hídrica durante o período crítico da soja;

2. Pode-se esperar redução de rendimento de grãos de soja em nove a cada vinte safras;

3. Os riscos por deficiência hídrica diminuem à medida que se atrasa a época de semeadura até o início de dezembro;

4. O escalonamento da semeadura e a utilização de cultivares de distintos grupos de maturação, podem reduzir os riscos causados pela deficiência hídrica. 


\section{REFERÊNCIAS BIBLIOGRÁFICAS}

BARNI, N.A.; MATZENAUER, R. Ampliação do calendário de semeadura da soja no Rio Grande do Sul pelo uso de cultivares adaptados aos distintos ambientes. Pesquisa Agropecuária Gaúcha, Porto Alegre, v.6, n.2, p.189-203, 2000

BERGONCI, J. I. et al. Eficiência da irrigação em rendimento de grãos e matéria seca de milho. Pesquisa Agropecuária Brasileira, Brasília, v.36, n.7, p.949-956, 2001.

BERLATO, M.A. Modelo de relação entre o rendimento de grãos de soja e o déficit hídrico para o Estado do Rio Grande do Sul. 1987. 93f. Tese (Doutorado em Meteorologia) - Curso de Pós-graduação em Meteorologia, Instituto Nacional de Pesquisas Espaciais, 1987.

BERLATO, M.A.; MATZENAUER, R.; BERGAMASCHI, H. Evapotranspiração máxima da soja e relações com a evapotranspiração calculada pela equação de Penman, evaporação do tanque "classe A" e radiação solar global. Agronomia Sulriograndense, Porto Alegre, v.22, n.2, p.243-259, 1986.

BISOTTO, V.; FARIAS, A.D. Algumas considerações sobre a cultura da soja. In: REUNIÃO DE PESQUISA DE SOJA DA REGIÃO SUL, 29., 2001, Porto Alegre. Indicações técnicas para a cultura da soja 2001. Porto Alegre : FEPAGRO, 2001. 138p.

CUNHA, G.R. et al. Perda de rendimento potencial em soja no Rio Grande do Sul por deficiência hídrica. Revista
Brasileira de Agrometeorologia, Santa Maria, v.6, n.1, p.111-119, 1998 .

MATZENAUER, R. et al. Relações entre rendimento de milho e variáveis hídricas. Revista Brasileira de Agrometeorologia, Santa Maria, v.3, p.85-92, 1995.

MATZENAUER, R. Análise agroclimática das disponibilidades hídricas para a cultura da soja na região do Planalto Médio do Rio Grande do Sul. Revista Brasileira de Agrometeorologia, Santa Maria, v.6, n.2, p.263-275, 1998.

MATZENAUER, $R$. et al. Consumo de água e disponibilidade hídrica para milho e soja no Rio Grande do Sul. Porto Alegre : FEPAGRO, 2002. 105p. (Boletim FEPAGRO, 10)

MATZENAUER, R. Estimativa do consumo relativo de água para a cultura do milho no Estado do Rio Grande do Sul. Revista Brasileira de Agrometeorologia, Santa Maria, v. 10, n.1, p.35-43, 2002.

MOTA, F.S. et al. Análise agroclimatológica da necessidade de irrigação da soja no Rio Grande do Sul. Revista Brasileira de Agrometeorologia, Santa Maria, v. 4, n.1, p.133-138, 1996.

PENMAN, H.L. Evaporation: and introductory survey. Netherland Journal of Agricultural Science, Wageningen, v. 4, p.9-29, 1956.

THORNTHWAITE, C.W.; MATHER, J.R. The water budget and its use in irrigation. Washington : Yearbook of Agriculture, 1955. p.346-358. 